\title{
"Pare de tocar seu rosto!": as mudanças na percepção dos espectadores do filme Contágio com a pandemia de COVID-19
}

Luisa Massarani',"l

https://orcid.org/0000-0002-5710-7242

Luiz Felipe Fernandes Neves'II

https://orcid.org/0000-0002-5994-9494

Penélope Andreani Valadares'

https://orcid.org/0000-0002-5661-0188

I - Instituto Nacional de Comunicação Pública da Ciência e Tecnologia (INCT-CPCT).

Rio de Janeiro (RJ). Brasil.

II - Casa de Oswaldo Cruz (COC/Fiocruz).

Rio de Janeiro (RJ). Brasil.

III - Instituto Oswaldo Cruz (IOC/Fiocruz).

Rio de Janeiro (RJ). Brasil.

Resumo: A pandemia de COVID-19 fez aumentar a procura pelo filme Contágio, um longa-metragem ficcional de 2011, cujo enredo aborda a disseminação em escala global de um novo vírus de transmissão respiratória, e que causa uma doença com alta taxa de letalidade. Neste artigo, utilizamos métodos mistos (dados quantitativos e análise qualitativa) para analisar 4.801 comentários sobre o filme, postados em uma rede social sobre cinema. Comparamos as avaliaç̃̃es antes e depois de janeiro de 2020, quando o novo coronavírus foi considerado pela Organização Mundial da Saúde uma emergência de saúde 
pública de importância internacional. A análise das palavras e termos mais frequentes, assim como da proximidade entre eles, revelou como a pandemia alterou a percepção dos espectadores, que passaram a avaliar o filme mais pela sua verossimilhança da situação sanitária que pelos seus aspectos cinematográficos. Também buscamos na própria obra cenas e elementos fílmicos que pudessem ter mobilizado a atenção do público para determinados aspectos revelados nos comentários, como formas de transmissão, medidas de higiene, distanciamento social e promoção de medicamento sem eficácia comprovada. Nesse sentido, os resultados também mostram o potencial do cinema para a divulgação científica ao abordar conceitos, temas, processos e controvérsias da ciência e da saúde.

Palavras-chave: filme Contágio; COVID-19; coronavírus; pandemia.

\begin{abstract}
Stop touching your face!": changes in the perception of viewers of the film Contagion with the COVID-19 pandemic - The COVID-19 pandemic has increased the search for the Contagion, a fictional feature film from 2011 whose plot addresses the global spread of a new respiratory transmitted virus, which causes a disease with a high mortality rate. In this paper, we used a quali-quantitative methodology to analyze 4,801 comments about the movie posted on a social network about cinema. We compared the assessments before and after January 2020, when the new coronavirus was considered by World Health Organization a public health emergency of international concern. The analysis of the most frequent words and terms and the proximity between them revealed how the pandemic changed the perception of the viewers, who started to evaluate the film more for its verisimilitude than for its cinematic aspects. We also sought in the movie itself scenes and film elements that could have mobilized the public's attention to certain aspects revealed in the comments, such as forms of transmission, hygiene measures, social distancing and promotion of medication without proven efficacy. In this sense, the results also show the potential of cinema for science communication when addressing scientific concepts, themes, processes, and controversies.
\end{abstract}

Keywords: Contagion; COVID-19; coronavirus; pandemic.

\title{
Introdução
}

O mundo já havia passado pelos surtos de Síndrome Respiratória Aguda Grave (SARS), em 2003, gripe aviária, em 2004, e pela pandemia de gripe AH1N1, em 2009, quando o filme hollywoodiano Contágio chegou aos cinemas. Lançado em 2011, o longa-metragem dirigido pelo norte-americano Steven Soderbergh tem como eixo narrativo a propagação de um vírus causador de uma nova doença e retrata um cenário apocalíptico em virtude de sua letalidade descontrolada. Quase uma década depois, a procura pelo filme aumentou de forma abrupta, alcançado o nível máximo de interesse 
medido pelo Google Trends entre os dias 15 e 21 de março de 2020 (GOOGLE, 2020). Contágio também passou a figurar entre os títulos mais buscados em diversas plataformas de streaming, à frente até mesmo de lançamentos atuais (CLARK, 2020; OLIVEIRA; GRAZINI, 2020; SPERLING, 2020).

O interesse pelo filme, nove anos depois de sua estreia, tem uma explicação: a pandemia de COVID-19 (Coronavirus Disease 2019), causada pelo novo coronavírus SARS-CoV-2. Isso porque a obra ficcional possui diversas semelhanças com o que tem ocorrido na realidade desde a virada de 2019 para 2020, quando a Organização Mundial da Saúde (OMS) foi informada do registro de pouco mais de 40 casos de uma pneumonia de origem desconhecida na cidade de Wuhan, na China, e que em pouco tempo tomou proporções globais (WHO, 2020b). Até o fim de fevereiro de 2021, a doença já tinha provocado mais de 2,5 milhões de mortes e infectado cerca de 114 milhões de pessoas em 221 países e territórios (WORLDOMETER, 2021).

O aumento da audiência de Contágio foi acompanhado pelas discussões em torno do filme em comunidades que reúnem apreciadores do cinema, corroborando o potencial de uma obra audiovisual para o debate público de assuntos diversos. Neste artigo, analisamos as avaliações publicadas pelos usuários de uma dessas plataformas - o site Letterboxd - desde o lançamento do filme até os dias atuais, com o objetivo de verificar possíveis mudanças na percepção dos espectadores sobre a obra cinematográfica depois que a COVID-19 foi oficialmente reconhecida como uma emergência de saúde pública de importância internacional (WHO, 2020c). A análise de 4.801 comentários revelou que a verossimilhança passou a ser um aspecto preponderante ao se avaliar o filme, levando o espectador a assimilá-lo de acordo com sua experiência pessoal, o que, nesse caso, incluiu informações e conceitos ligados à ciência e à saúde.

\section{Em cartaz: surtos, epidemias e pandemias}

Doenças desconhecidas e emergências sanitárias já foram inspiração para roteiros da indústria cinematográfica em diversos países. Alguns exemplos são: O Enigma de Andrômeda (Robert Wise, 1971); Epidemia (Wolfgang Petersen, 1995); Os 12 Macacos (Terry Gilliam, 1995); Ensaio Sobre a Cegueira (Fernando Meirelles, 2008); Deranged (Park Jung-woo, 2012); A Gripe (Kim Sung-su, 2013); 93 Dias (Steve Gukas, 2016); Vírus (Aashiq Abu, 2019). Mainero e Covarrubias (2014) lembram que filmes sobre surtos e epidemias nos 
recordam da interminável luta do homem contra as doenças, cujas consequências catastróficas marcam diversos períodos da história.

Contágio estreou em 9 de setembro de 2011 e foi escrito pelo roteirista Scott Z. Burns. O filme gira em torno da ameaça de um surto de uma doença altamente letal, causada por um vírus de origem zoonótica, que tem início em Hong Kong. À medida que a epidemia cresce rapidamente, a comunidade médica mundial, junto ao Centro de Controle e Prevenção de Doenças dos Estados Unidos (CDC, na sigla em inglês) e à OMS, tentam encontrar uma cura e conter o vírus fictício MEV-1. O elenco é constituído por atores premiados e renomados, como Matt Damon, Gwyneth Paltrow, Kate Winslet, Marion Cotillard, Jude Law e Laurence Fishburne.

Para escrever o roteiro, Scott Z. Burns estudou a ciência por trás das pandemias. Ele conversou com epidemiologistas, entre eles Lawrence "Larry" Brilliant, um dos responsáveis por erradicar a varíola e que o apresentou a outros cientistas da Columbia University. O roteirista ainda visitou o CDC em Atlanta para aprender sobre o funcionamento de um órgão de saúde pública em momentos de calamidade (ADOLFO, 2020). O diretor Steven Soderbergh também afirmou que tentou ser rigoroso com o caráter científico, e que a maior cessão à verossimilhança foi a rapidez na criação da vacina, que no filme é desenvolvida em poucos meses e que tem como prova de conceito a autoaplicação do imunizante pela própria cientista responsável (BUCHANAN, 2020).

Na área acadêmica, Contágio foi utilizado em estudos sobre mídia-educação em escolas, sendo um recurso motivador para a análise do conhecimento prévio de estudantes do ensino médio (BALBINOT; MIQUELIN, 2013; MIQUELIN; BALBINOT, 2014), como mediador na aprendizagem significativa sobre o tema epidemia (BORBA, 2015) e para discutir conceitos e medidas de prevenção (MENDONÇA; PINHEIRO, 2019). Outros temas e conceitos abordados a partir da narrativa foram o de evolução biológica (SILVA JÚNIOR, 2016) e o de fake news, na perspectiva dos movimentos antivacina (GRAVINA; MUNK, 2019).

Outros estudos relatam o emprego da obra cinematográfica em universidades: no curso de medicina, como suporte para o aprendizado sobre microbiologia e doenças infecciosas (MARTíNEZ et al., 2013) e sobre métodos clínicos e epidemiológicos (DOMíNGUEZ; CASTELLANOS, 2016); no ensino de enfermagem, para a elucidação do perioperatório (termo que designa todo o período de uma cirurgia, do antes ao pós-operatório), tendo como enfoque 
o desenvolvimento de competências e habilidades do aluno (MESSIAS et al., 2019); e no curso de odontologia, para o ensino de epidemiologia e saúde pública (FIDALGO, 2019).

No campo de análise audiovisual, o filme é mencionado em trabalhos que tratam dos limites da representação realista de uma pandemia (BENSONALLOT, 2011; MÜLLER, 2013; GÓMEZ, 2020; DAVIS, 2017), do imaginário pósapocalíptico no cinema atual e das diversas narrativas e concepções culturais contidas em tais representações (IMBERT, 2014; SIKORA, 2014; SUGIERA, 2017; MARKENDORF; FELIPPE, 2018; BLANES, 2018), além da retórica da saúde e segurança global (POKORNOWSKI, 2013; BAKER, 2013). Em uma perspectiva antropológica, é analisada a dinâmica social diante do surgimento de uma pandemia com elevada mortalidade (KORSTANJE, 2012; ROJAS, 2017), assim como características ideológicas (KORSTANJE, 2017), etnocêntricas, sociais e geográficas (BARBOSA, 2020; ATOCHERO, 2020).

Pesquisas sobre saúde e doenças infecciosas também citam a importância do filme em trabalhos que relacionam o vírus que serviu de inspiração (LEE, 2011), a medicina genômica (MAINERO; COVARRUBIAS, 2014), a saúde pública e o empoderamento do cidadão (DELEO, 2014), o surto infeccioso fictício verossímil cientificamente (LOMAN; GARDY, 2015) e a curiosidade mórbida como preferência da mídia durante uma pandemia (SCRIVNER, 2020). Outros estudos são relativos às representações sociais e sobre a globalização como instrumento da disseminação de doenças, geografia humana (JUDENSNAIDER, 2012; DIXON; JONES, 2015), representação do estado de exceção no cinema pandêmico (VENTOSA, 2015) e a representação social de morcegos na mídia (CAPPARROS; MAGALHÃES JÚNIOR, 2015).

A diversidade de abordagens mostra que, por ser um "sistema de significados" (ANDREW, 2002), um filme pode ser explorado e ter aplicações para além do entretenimento e, consequentemente, também pode ser analisado em suas várias dimensões, por áreas de conhecimento diversas, como o ensino, a pedagogia, a biologia, a saúde, o audiovisual e as ciências sociais de uma forma geral. No presente estudo, propomos avançar em mais um aspecto: a análise da articulação de uma obra cinematográfica às conversações e relações estabelecidas por seus espectadores no ambiente digital, além das representações e apropriações da ficção e da realidade, a partir de uma trama que é descoberta ou revisitada em função de uma crise sanitária global que ameaça a vida da população. Para dar conta desse objetivo, procuramos utilizar ferramentas metodológicas que respondessem a essas particularidades, como será visto nas próximas seções. 


\section{Metodologia}

Letterboxd é uma rede social focada no compartilhamento de opiniões sobre filmes, que pode ser acessada por meio do site ou aplicativo para dispositivos móveis. Ao criar seu perfil, o usuário pode avaliar filmes (atribuindo estrelas), publicar comentários e compartilhá-los na plataforma (LETTERBOXD, 2020). A rede foi criada em 2011, por Matthew Buchanan e Karl von Randow, com sede em Auckland, na Nova Zelândia. A escolha do Letterboxd para o presente estudo deve-se ao fato de se tratar de uma das maiores redes sociais mundiais para cinéfilos e de recomendações de filmes. Além disso, em março de 2020, Contágio estava no topo da lista de filmes mais populares da plataforma (GRACEWOOD, 2020).

O corpus foi composto por avaliações do filme, coletadas em 24 de outubro de 2020. Até aquela data, haviam sido publicados 16.290 comentários sobre Contágio, dos quais 6.144 estavam disponibilizados no site ${ }^{1}$. Foram excluídas publicações em idiomas diferentes do inglês ou compostas apenas por caracteres não textuais (emoticons), resultando em uma amostra final de 4.801 avaliações feitas entre agosto de 2011 e outubro de $2020^{2}$. A extração dessa grande quantidade de texto foi feita de forma automatizada, com a utilização de algoritmos para raspagem de dados desenvolvidos para a linguagem de programação Python.

Como as notas podem ser dadas de meia em meia estrela, para os fins desta análise, foram definidas dez possíveis notas que poderiam ser atribuídas pelos usuários - cinco na faixa mais baixa $(0,5$ a 2,5) e cinco na faixa mais alta ( 3 a 5). Além disso, foi feito um recorte temporal da amostra, de modo a dividi-la entre antes e depois da pandemia de COVID-19. Para isso, foi estabelecido o marco temporal de 30 de janeiro de 2020, dia em que a OMS declarou o novo coronavírus como uma emergência de saúde pública de importância internacional (WHO, 2020c).

Para a análise, foi utilizado o software WordStat 6, que processa estatisticamente grandes quantidades de texto. O programa identifica e contabiliza as palavras e expressões mais frequentes, considerando o maior peso nas avaliações. Como o corpus é composto, em sua maioria, por textos curtos,

1 Embora o site informe o total de comentários publicados sobre um filme, ele disponibiliza para visualização apenas uma parte deles.

2 Consideramos apenas os comentários em inglês por ser este o idioma utilizado em quase todos os comentários. Na apresentação dos resultados, embora as imagens geradas pelo software mostrem as palavras e expressões em inglês, ao se referir a elas no texto optamos por traduzi-las para o português, para facilitar a compreensão do leitor. 
o resultado foi ordenado de acordo com o percentual de comentários em que determinada palavra ou expressão foi utilizada.

Além disso, foram utilizadas as ferramentas de clusterização e escalonamento multidimensional para a análise da coocorrência de palavras e de expressões. O programa calcula a proximidade entre os termos do corpus, gerando como representação gráfica um mapa conceitual de palavras e expressões, representado por círculos coloridos (cada cor representa um dos agrupamentos hierárquicos formados na análise de cluster), de tamanhos diferentes (quanto maior o círculo, maior a frequência do item) e em que a distância entre os círculos demonstra a probabilidade de os termos ocorrerem próximos uns dos outros na mesma frase. Por utilizar métodos mistos - dados quantitativos e análise qualitativa - , este estudo caracteriza-se como de abordagem quali-quantitativa.

\section{Resultados}

A maior parte da amostra coletada é composta por críticas com avaliações mais altas - são 3.420 com notas entre 3 e 5 estrelas, o que equivale a $71,2 \%$ do total. O restante $-28,8 \%$ - está na faixa de avaliações mais baixas, ou seja, entre 0,5 e 2,5. A nota 4,5 foi a mais frequente, atribuída por 974 usuários. A proporção entre esses comentários é semelhante antes e depois da declaração de emergência em saúde pública feita pela OMS. Nos dois períodos, cerca de dois terços dos usuários deram notas mais altas ao filme. Bom e excelente são os adjetivos mais utilizados nesses textos, aparecendo em cerca de $10 \%$ deles. Embora essas palavras também sejam frequentes nas críticas com notas mais baixas, observa-se a recorrência dos usuários ao termo entediante como a principal característica negativa do filme.

No momento da publicação de uma crítica, o site Letterboxd permite que seja informada a data em que o filme foi assistido ou se já havia sido visto anteriormente. Da amostra analisada, $92 \%$ dos usuários preencheram essa informação. Apesar de a maioria ter afirmado que assistiu ao filme pela primeira vez, a maior parte dos usuários que indicaram já o terem visto $91,2 \%$ - atribuiu notas mais altas, o que seria condizente com o fato de que o espectador decidiu ver o filme novamente. Além disso, 81,3\% deles se concentram no período depois da declaração da OMS. Isso significa que, com a crise do novo coronavírus já em curso, 906 usuários reassistiram ao filme e postaram suas críticas. 
Esse resultado pode ser complementado com a análise textual das palavras e frases mais frequentes nos dois recortes do corpus (Figuras 1 e 2). Isso porque os verbos assistir e assistindo aparecem com bastante destaque no período pós-pandemia (são a segunda e a nona palavras mais frequentes, respectivamente). Ao se checar o contexto em que foram empregadas, é possível perceber a ênfase dos espectadores no fato de estarem assistindo ao filme em meio a uma emergência sanitária, semelhante à do enredo, o que motiva reações tanto positivas quanto negativas.

"Fascinante assistir a isso durante uma pandemia. A tensão é muito mais real." (Avaliação de nayanc, 06/04/2020, nota 4,5).

“Não assiste a isso agora, cara. Vamos esperar até que esteja melhor." (Avaliação de OlmO, 30/03/2020, nota 1) (LETTERBOXD, 2020, tradução nossa) ${ }^{3}$.

\section{SODERBERGH CAST TIME}

\section{GREAT VIRUS WORLD PEOPLE GOOD}

\section{CHARACTERS STORY JUDE WATCH MATT FILMS}

MOVIES REAL MAKE CHARACTER THRILLER DISEASE GWYNETH

OUTBREAK END INTERESTING LOVE REALISTIC EPIDEMIC MAKES

KATE LOT SPREAD FEEL SCORE PANDEMIC WORK PLOT DAY PERFORMANCES PRETTY HAPPEN THINGS HANDS WATCHING THING LIFE KIND BIG FEELS HORROR

FELT THOUGHT FACT DISASTER MARION BORING FEAR SICK SCARY TERRIFYING CURE

POINT BIT TIMES ACTORS PART ENSEMBLE WATCHED BAD DIE LAURENCEE PERFECT

SCENES HUMAN SENSE PANIC STAR DIRECTOR WASH NARRATIVE TOUCH ACTING SHOW

GLOBAL ENDING FACE SHOT STORIES HALF SCIENCE FLU LOVED CARE SHOWS GENRE

FANTASTIC AUDIENCE REALISM

Figura 1. Nuvem de palavras dos comentários anteriores à declaração da OMS. Fonte: elaborado pelos autores.

\section{PANDEMIC WATCH SODERBERGH TIME VIRUS GOOD PEOPLE COVID WATCHING CORONAVIRUS REAL GREAT WORLD WATCHED CHARACTERS CURRENT CAST STORY MATT JUDE CHARACTER PRETTY FEEL LIFE TIMES LOT ACCURATE INTERESTING THING THINGS SCORE FEELS MAKE GWYNETH SCARY FELT END SITUATION PLOT MAKES MOVIES REALISTIC BAD THOUGHT SOCIAL DISEASE BIT OUTBREAK SHIT YEARS DAY FILMS POINT HANDS KATE ENDING TERRIFYING VACCINE LOVE TODAY RELEVANT GLOBAL WORK BORING REALITY EVENTS KIND SCENE PART HAPPENING MARION STAR PERFORMANCES DISTANCING SPREAD HALF HOME FACE THRILLER BIG SIMILAR SHOW}

Figura 2. Nuvem de palavras dos comentários posteriores à declaração da OMS. Fonte: elaborado pelos autores. 
A análise estatística do texto revela ainda como a COVID-19 alterou o léxico nas críticas ao filme Contágio. A palavra pandemia, por exemplo, é a mais frequente entre os comentários feitos depois do marco temporal estabelecido, estando presente em pouco mais de 14\% deles. É o dobro da presença verificada nas avaliações anteriores, nas quais as palavras surto e epidemia são mais empregadas para se referir à situação retratada pelo filme, mas ainda assim surgindo com frequência menor. 0 mesmo ocorre com as palavras coronavírus e covid, praticamente não utilizadas antes, mas que estão entre as dez mais frequentes nas críticas atuais. Vale lembrar que o nome COVID-19 foi divulgado pela OMS apenas no dia 11 de fevereiro de 2020 (WHO, 2020a).

De forma geral, o que se percebe na comparação entre as nuvens de palavras é que, nas avaliações anteriores à pandemia, as críticas giram mais em torno de aspectos cinematográficos, relacionados principalmente à direção, ao elenco e aos personagens. Observa-se, por exemplo, que as palavras Soderbergh e elenco são as duas mais utilizadas nesses textos. Entre as mais frequentes nesse aspecto também estão personagens, Jude, Matt e Gwyneth. Embora o nome do diretor esteja com certo destaque no período posterior, ele aparece em uma quantidade menor de avaliações $(12,8 \%)$, da mesma forma que os nomes dos atores e atrizes.

Os mapas conceituais corroboram essa percepção, na medida em que permitem visualizar mais claramente a incidência das palavras (tamanho dos círculos), a coocorrência na mesma frase (proximidade dos círculos) e a formação de clusters (divisão por cores). Na Figura 3, relativa aos textos publicados anteriormente: o conjunto mais evidente está delimitado à esquerda pela cor rosa, com a maioria das referências relacionada ao elenco. Seguindo no sentido horário, pelo menos outros três clusters também são mais voltados à narrativa e aos personagens. Já na Figura 4, 0 cluster dominante (em azul) é composto por palavras diretamente relacionadas à pandemia de COVID-19 e à relação do filme com a atualidade. Menções aos atores e ao enredo estão reunidas na parte inferior direita do mapa, com menos destaque. 


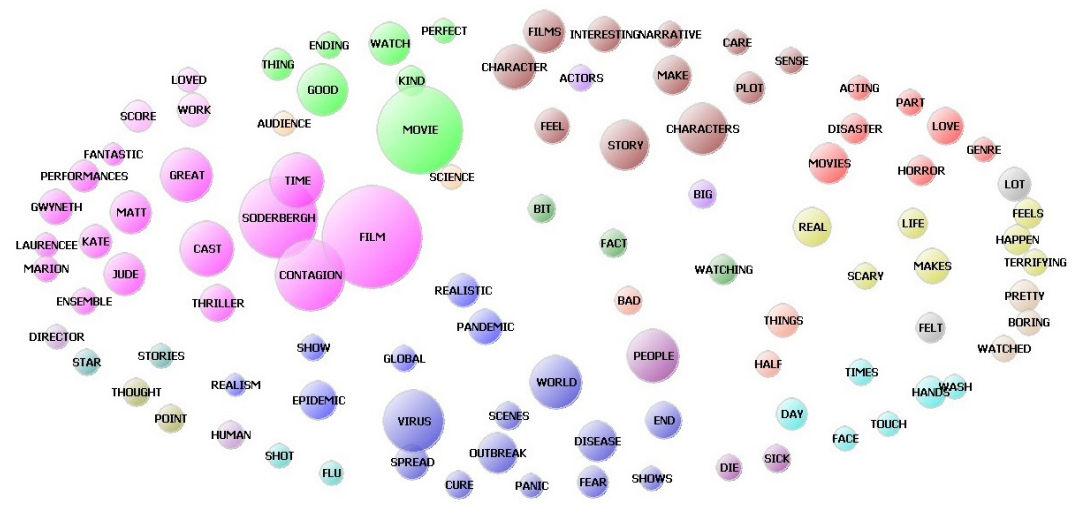

Figura 3. Mapa conceitual dos comentários anteriores à declaração da OMS. Fonte: elaborado pelos autores.

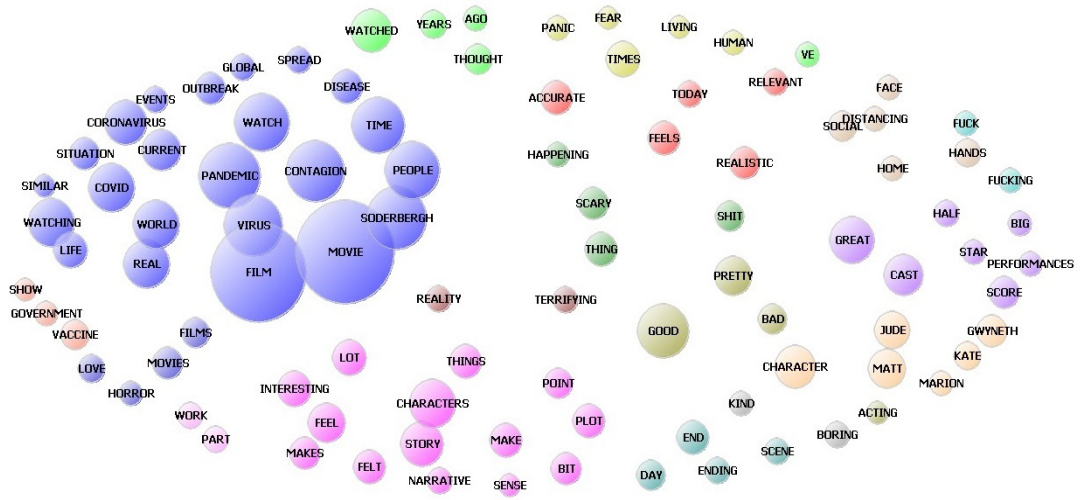

Figura 4. Mapa conceitual dos comentários posteriores à declaração da OMS. Fonte: elaborado pelos autores.

Essa alteração no foco das críticas fica ainda mais evidente com a análise das expressões mais frequentes (Figuras 5 e 6). Ensemble cast ${ }^{4}$ é a mais empregada nas avaliações feitas antes do novo coronavírus. Com certo destaque, também aparecem as expressões "elenco de estrelas" e "ótimo elenco". No outro conjunto de avaliações, referências ao elenco começam a surgir somente a partir da $15^{\mathrm{a}}$ expressão mais frequente. Em mais evidência, estão termos relacionados aos fatos da atualidade: vida real, situação atual, pandemia de covid, pandemia atual, mundo real, pandemia do coronavírus, eventos atuais.

4 A expressão ensamble cast é usada na cinematografia para designar um elenco em que vários atores possuem a mesma importância na narrativa (MATHIJS, 2011). A tradução literal para o português seria "elenco conjunto", mas como não há tradição no uso desse termo traduzido, referimo-nos a ele como no original em inglês. 


\section{ENSEMBLE CAST WASH YOUR HANDS} DEADLY VIRUS REAL LIFE WASH MY HANDS GLOBAL PANDEMIC STAR CAST DISEASE CONTROL END OF THE WORLD HONG KONG GREAT CAST HORROR FILM DISASTER MOVIE WORLD WAR SODERBERGH FILM REAL WORLD MILLIONS OF PEOPLE PRETTY GOOD WATCHING CONTAGION SIDE EFFECTS VE WATCHED TOP NOTCH DISASTER FILMS STOP TOUCHING HORROR MOVIE ALAN KRUMWIEDE CONSPIRACY THEORIST SCREEN TIME

WORLDWIDE EPIDEMIC WORLD HEALTH ORGANIZATION DISASTER MOVIES DISASTER FILM GREAT MOVIE GREAT FILM LONG TIME AUSTRALIAN ACCENT GOOD MOVIE STUDDED CAST GOOD FILM TALENTED CAST MILLION PEOPLE DIRECTOR SODERBERGH HORROR MOVIES GREAT PERFORMANCES CENTERS FOR DISEASE CONTROL KIND OF MOVIE SCORE BY CLIFF LOVE THIS MOVIE

Figura 5. Nuvem de expressões dos comentários anteriores à declaração da OMS. Fonte: elaborado pelos autores.

\section{SOCIAL DISTANCING REAL LIFE GLOBAL PANDEMIC YEARS AGO GOOD MOVIE CURRENT SITUATION WASH YOUR HANDS PRETTY GOOD COVID PANDEMIC CURRENT PANDEMIC REAL WORLD TOILET PAPER CORONAVIRUS PANDEMIC WATCHING THIS MOVIE DEADLY VIRUS HORROR FILM CURRENT EVENTS GREAT MOVIE ENSEMBLE CAST CONSPIRACY THEORIST STAY SAFE GREAT CAST WATCH THIS MOVIE WATCHED THIS MOVIE STOP TOUCHING CHARACTER DEVELOPMENT SCARILY ACCURATE CLOSE TO HOME MOVIE TO WATCH TOUCHING YOUR FACE HONG KONG PLOT LINES WATCHING CONTAGION FINAL SCENE GOOD FILM STAR CAST MORTALITY RATE DISASTER MOVIE HORROR MOVIE SUBJECT MATTER PUBLIC HEALTH CURRENT COVID GREAT FILM STOP TOUCHING YOUR FACE MIDDLE OF A PANDEMIC WATCHING THIS FILM WEAR A MASK WATCH THIS FILM \\ Figura 6. Nuvem de expressões dos comentários posteriores à declaração da OMS. Fonte: elaborado pelos autores.}

Nas nuvens de expressões, também é perceptível o incremento no vocabulário relacionado às medidas de prevenção a uma doença de transmissão por vias respiratórias. Nos comentários pré-pandemia, a medida mais lembrada pelos usuários foi o ato de lavar as mãos ("lave as mãos" e "lavo minhas mãos"). Já nas críticas posteriores, distanciamento social é o termo de maior destaque. É importante registrar ainda que, embora pouco recorrentes, expressões como "usar uma máscara" e "desinfetante para as mãos" aparecem somente nas avaliações pós-pandemia. Por fim, nos dois recortes, há menções à expressão "pare de tocar seu rosto". Trata-se de uma fala da médica do CDC, personagem de Kate Winslet, ao ser questionada pelo seu assistente sobre um possível exagero em relação às medidas de higiene.

Dave: Minha esposa me faz tirar a roupa na garagem, depois deixa um balde com água morna e um pouco de sabão. E então ela encharca tudo no desinfetante depois que eu saio. Quero dizer, ela está exagerando, certo? 
Dra. Mears: Na verdade, não. E pare de tocar seu rosto, Dave (CONTÁGIO, 2011, 37 min 42 s, tradução nossa) $)^{5}$.

Por fim, os dados revelam que o uso de termos relacionados ao medo e à preocupação foi mais frequente nos comentários postados antes da pandemia de COVID-19. As palavras terror e catástrofe são geralmente empregadas nos textos desse período para designar o gênero do filme. 0 site Letterboxd categoriza Contágio como drama, ficção científica e suspense. Nos comentários, usuários o classificam como terror (horror film) ou filmecatástrofe (disaster movie). Medo, assustador e aterrorizante também estão entre as palavras utilizadas nesse contexto, mas com uma incidência menos frequente no conjunto de avaliações postadas após a declaração de emergência do novo coronavírus. Nos mapas conceituais, percebe-se que os termos relacionados ao temor da doença estão quase sempre próximos, ou no mesmo cluster de expressões referentes à realidade atual (acontece, acontecendo, realidade, realístico, vivendo).

\section{Discussão}

A partir dos resultados, é possível notar que, ainda que a pandemia de COVID-19 não tenha alterado a proporção entre as avaliações com notas mais altas e mais baixas dadas ao filme, a verossimilhança torna-se um fator preponderante nos comentários publicados antes e depois do novo coronavírus. Ou seja, Contágio passa a chamar mais atenção e a ser avaliado muito mais pela acurácia com que "previu" um evento do que pela direção ou atuação do elenco. Entretanto, não se pode minimizar o peso de estrelas hollywoodianas na atenção gerada pelo filme (KEANE, 2006), como revelam os frequentes elogios ao diretor e aos atores e atrizes, observados em todos os recortes do corpus.

É nesse sentido que Gómez (2020) afirma que Contágio pode ser considerado o filme com maior correspondência em relação à realidade de uma pandemia, devido ao seu rigor no tratamento de dados e procedimentos científicos, sem incorrer nas desproporções típicas da espetacularização. Entretanto, segundo o autor, essa qualidade mais notável pode ser ao mesmo tempo um inconveniente, pois a sobriedade da narrativa confere-lhe, apesar do seu

5 "Dave: My wife makes me take off my clothes in the garage, then she leaves out a bucket of warm water and some soap. And then she douses everything in hand sanitizer after I leave. I mean, she's overreacting, right? Dr. Mears: Not really. And stop touching your face, Dave". (CONTÁGIO, 2011, $37 \mathrm{~min} 42 \mathrm{~s})$. 
bom ritmo, um tom monótono generalizado, o que transparece no corpus deste estudo com o adjetivo entediante, utilizado nas avaliações negativas.

Nesse sentido, Contágio se soma às inúmeras representações do imaginário ficcional das doenças, transpostas para diversas narrativas ao longo da história da humanidade, denominadas por Markendorf e Felippe (2018) como a estética da catástrofe.

Ao que parece, um cenário de enfermidade pode expressar a suspensão da moral e dos afetos, algo que prevê o instalar dos desafetos e o domínio do comportamento moral/amoral sobre o Outro. As epidemias, portanto, carregam consequências políticas e as metáforas epidêmicas que as circundam são estetizadas, fato que sugere a construção de uma poética epidêmica, ou ainda, de uma estética da catástrofe (MARKENDORF; FELIPPE, 2018, p. 310-311).

Embora o roteiro tenha equiparado seu vírus fictício à SARS e à H1N1 na cena em que a cepa da MEV-1 é armazenada com as dos vírus que existem na vida real, pode-se dizer que, até o surgimento da COVID-19, o enredo talvez representasse para os espectadores uma situação extrema que, embora factível, parecia distante da realidade, o que é típico de um filmecatástrofe, em sua atmosfera de medo e terror. Entre as características desse gênero, Keane (2006) destaca o grupo de personagens que enfrenta situações perigosas, o questionamento sobre quem vai sobreviver no final e as sequências catastróficas. Além disso, as doenças reais mencionadas em Contágio (SARS e H1N1) foram bem menos letais que a atual COVID19 , criando um paralelo que, até 2020 , não tinha sido vivenciado pela atual geração. Sendo assim, é sintomático que uma parcela de usuários tenha revisitado o filme em 2020, atribuindo-Ihe majoritariamente notas mais altas. Em síntese, com a pandemia do novo coronavírus, o medo gerado por uma trama fictícia de um filme-catástrofe é substituído pelo espanto diante de sua transposição, quase literal, para a realidade. Contágio, portanto, se enquadra na categoria de filmes "[...] trágicos em seu desenlace e antecipatórios em suas intenções" (FOURNIER, 2019, p. 1, tradução nossa) ${ }^{6}$.

As medidas de prevenção mencionadas com mais frequência pelos usuários reforçam o potencial de uma obra cinematográfica para a comunicação da ciência. A maior incidência do termo lave suas mãos entre as avaliações 
feitas no período pré-pandemia, por exemplo, não é fortuita. Todo o filme é permeado por sequências e enquadramentos fechados nas mãos dos personagens, reforçados pelo áudio ambiente preenchido com pessoas falando e tossindo. A primeira cena ilustra exatamente essa linha condutora empregada pelo diretor: o filme começa com uma tela preta e apenas o som que sugere um lugar movimentado e alguém tossindo. Na sequência, surge a personagem Beth Emhoff (Gwyneth Paltrow), sentada no balcão de um bar no aeroporto, levando a mão à boca, atendendo o celular e entregando o cartão de crédito à atendente. A cena termina com o quadro fechado nas mãos da balconista.

Ao longo de toda a narrativa, a transmissão do vírus por superfícies é enfatizada ainda mais claramente, como na cena em que a médica Erin Mears explica as particularidades da doença a autoridades governamentais.

Dra. Mears: Então, até este momento, acho que temos que acreditar que isso é respiratório. Talvez fômites também.

Homem: O que é isso? Fômites?

Dra. Mears: Refere-se à transmissão por superfícies. Uma pessoa toca o rosto em média duas ou três mil vezes por dia.

Mulher: Duas ou três mil vezes por dia?

Dra. Mears: De três a cinco vezes a cada minuto acordado. Nesse intervalo, tocamos em maçanetas, bebedouros, botões de elevador e uns nos outros. Essas coisas se tornam fômites (CONTÁGIO, 2011, 17 min 57 s, tradução nossa) $)^{7}$.

Já o distanciamento social, mesmo que esteja contido em toda a história, é abordado de forma menos explícita. A medida é mencionada diretamente apenas uma vez, quando o diretor do CDC, Dr. Ellis Cheever (Laurence Fishburne) participa de uma entrevista na televisão.

Dr. Cheever: Bem, Dr. Gupta, vários medicamentos con-

7 "Dr. Mears: So, at this point, I think we have to believe this is respiratory. Maybe fomites, too. Man: What's that? Fomites? Dr. Mears: It refers to transmission from surfaces. The average person touches their face 2,000 or 3,000 times a day. Woman: 2,000 or 3,000 times a day? Dr. Mears: Three to five times every waking minute. In between, we're touching doorknobs, water fountains, elevator buttons and each other. Those things become fomites". (CONTÁGIO, 2011, 17 min 57 s). 
tinuam sendo avaliados. A ribavirina está entre eles. Mas neste momento nossa melhor defesa tem sido o distanciamento social. Nada de aperto de mão, ficar em casa quando estiver doente e lavar as mãos com frequência (CONTÁGIO, 2011, 1 h 2 min 52 s, tradução nossa) $)^{8}$.

Portanto, o surgimento do termo distanciamento social entre os mais frequentes nas avaliações pós-pandemia indica como o filme passou a ser assimilado de acordo com a experiência pessoal do espectador, submetido a medidas de isolamento social sem precedentes na história recente. Pode-se incluir nesse "repertório adquirido" imagens que antes não eram tão comuns para o público: uso de máscaras no cotidiano, cientistas trabalhando em laboratórios com alto nível de segurança (o filme menciona o Biosafety Level 3), simulações computadorizadas do vírus, ginásios transformados em hospitais de campanha e corpos enterrados em vala comum (Figura 7).
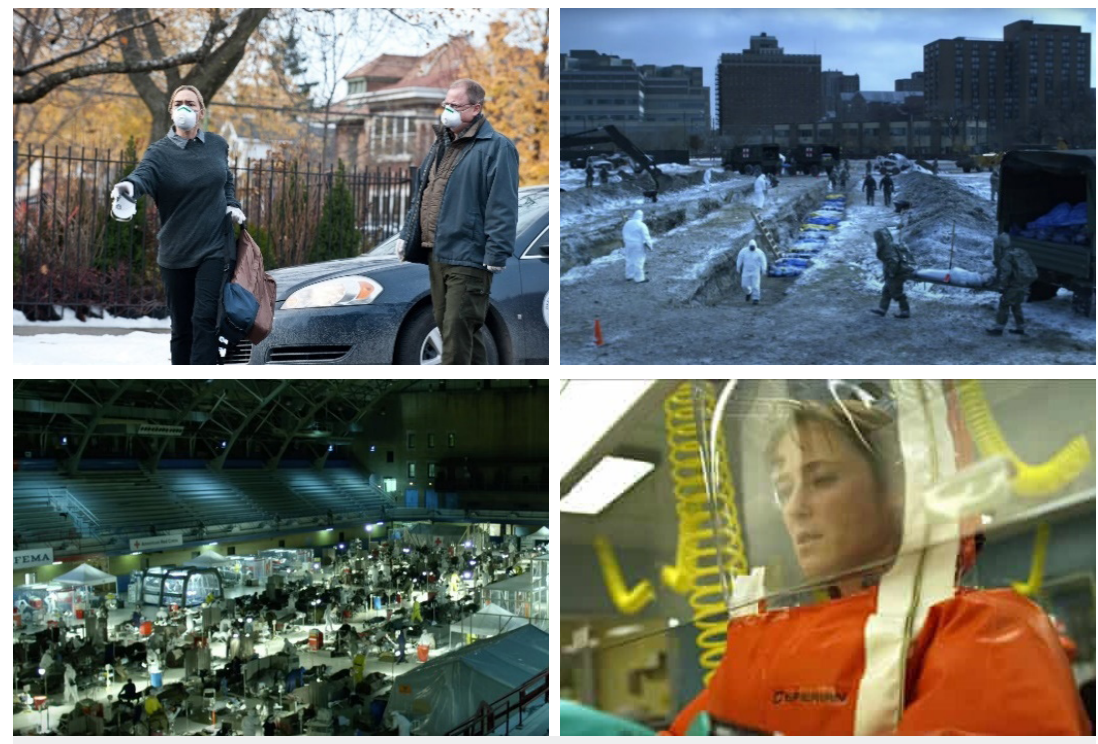

Figura 7. Frames do filme Contágio: pessoas usando máscara, enterros de corpos em valas comuns, hospital de campanha e cientista em laboratório de segurança máxima. Fonte: Contágio (2011)

O mesmo vale para alguns conceitos científicos explicados no roteiro como número básico de reprodução (R0 ou r-naught) e paciente zero (index patient) — ou mesmo para a cena final, que reconstrói didaticamente 
os fatos que levaram ao surto: o desmatamento que destrói o habitat natural de morcegos; a migração desses animais para uma granja de porcos; o preparo da carne suína em um restaurante (momento em que o vírus "salta" para o ser humano); e o aperto de mão entre o chef de cozinha e uma cliente (momento em que o vírus começa se espalhar).

Tais exemplos reforçam os resultados obtidos por Balbinot e Miquelin (2013), Miquelin e Balbinot (2014), Borba (2015) e Mendonça e Pinheiro (2019), com a utilização do filme como recurso didático motivador da análise dos conhecimentos prévios de estudantes da educação básica, como mediador da aprendizagem significativa, como instrumento de verificação das percepções desses jovens acerca do tema epidemia e de medidas de prevenção. Entretanto, trazemos para a discussão a ressalva de Piassi e Pietrocola (2009), que problematizam a noção de que o potencial didático de uma obra ficcional é muitas vezes associado somente à precisão científica das situações retratadas.

Assim, filmes que exibem cenas fantasiosas ou mesmo flagrantemente contrárias ao conhecimento científico seriam didaticamente menos relevantes do que as que trazem situações realistas. (PIASSI; PIETROCOLA, 2009, p. 527).

Trata-se de uma visão mais ampla do potencial de uma obra cinematográfica, para além da simples explicação de conceitos científicos - função à qual a comunicação da ciência também não deve se restringir.

A FC [ficção científica] tem sua própria maneira de falar sobre ciência, que é uma maneira que não encontramos mesmo em outras expressões ficcionais que falam da ciência. Ela é didática, porque se propõe a veicular ideias, mas não no sentido de explicar o que é a ciência ou ensinar conceitos científicos, embora isso possa ocorrer ocasionalmente. O que ela veicula, acima de tudo, são as questões que incomodam ou estimulam as pessoas, e que são questões originadas na ciência e na nossa relação sociocultural com ela (PIASSI; PIETROCOLA, 2009, p. 536).

Para os referidos autores, a ficção científica também pode levantar debates e questões em voga no momento de produção das obras. É nesse sentido que destacamos a importância das controvérsias científicas abordadas em Contágio, que parecem ter chamado mais a atenção dos usuários que avaliaram o filme. Uma delas está centrada no personagem Alan Krumwiede, 
interpretado por Jude Law. Trata-se de um jovem conspiracionista que usa a internet para disseminar informações falsas e para vender um medicamento - a forsítia - com a promessa de cura da MEV-1. Entre os nomes dos atores e atrizes, Jude é o que aparece no maior percentual de comentários (mais de 7\%). O nome do ator é citado em contextos diversos (há elogios e críticas), mas é interessante notar que, nas avaliações feitas depois da pandemia, seu nome e o de seu personagem são diretamente associados ao de Alex Jones, um apresentador de rádio norte-americano conhecido por disseminar teorias da conspiração. Em março de 2020, Jones foi notificado pela Procuradoria-Geral do estado de Nova York por anunciar produtos que combateriam o novo coronavírus, mesmo sem qualquer comprovação científica (FERRÉ-SADURNí; MCKINLEY, 2020).

\section{Considerações finais}

O rigor do método científico, associado ao avanço tecnológico, tem aprimorado o potencial da ciência de fornecer prognósticos sobre a realidade futura. Em março de 2019, por exemplo, Fan et al. (2019) já haviam publicado uma revisão sobre diversidade viral, hospedeiros e distribuição geográfica de coronavírus de morcegos na China, com a conclusão de que "[...] não devemos subestimar a possibilidade de recombinação entre diferentes CoVs de morcegos que levam à geração de potenciais vírus pandêmicos" (FAN et al., 2019, p. 7, tradução nossa) ${ }^{9}$. Quando o potencial preditivo da ciência encontra o fértil imaginário de escritores, roteiristas e diretores, os resultados podem ser obras de ficção que surpreendam pela semelhança com a realidade, como o filme Contágio, de 2011, representa para a pandemia de COVID-19, que teve início nove anos depois. Gómez (2020) lembra que a catástrofe sempre foi uma atração hipnótica, que combina a segurança da contemplação distante e a adrenalina apavorante da experiência. O cinema, segundo o autor, intensificou essa experiência com suas possibilidades de imersão sensorial.

O desenrolar dos acontecimentos reais, desde o início de 2020, levou a uma associação direta com a obra ficcional, então (re)descoberta nos atuais serviços de streaming, o que nos motivou a investigar possíveis mudanças na percepção dos espectadores. Para isso, utilizamos métodos quantitativos e qualitativos para contabilizar e analisar palavras e termos mais frequentes, 
além da proximidade e associação entre eles, em 4.801 comentários publicados em uma rede social dedicada ao cinema. Conclui-se que houve uma clara mudança na percepção dos espectadores de Contágio depois da COVID-19 se tornar uma emergência de saúde pública com importância internacional. Para esses usuários, a verossimilhança passou a ser a característica de destaque do filme.

Vale ressaltar que a utilização de ferramentas computacionais, ainda que abra a possibilidade de novos caminhos metodológicos para a exploração da grande e crescente quantidade de dados que caracteriza o cenário comunicacional contemporâneo (CASTELFRANCHI, 2017), não é exaustiva e tampouco exime o pesquisador de imergir em seu objeto de estudo, em busca dos contextos e sentidos que orientem a interpretação dos resultados. Nesse sentido, também buscamos, na própria obra, cenas e elementos fílmicos (planos, diálogos, cenários e caracterização) que contribuíssem para explicar a mobilização da atenção do público para determinados aspectos revelados em seus comentários, como as formas de transmissão de um vírus respiratório, medidas básicas de higiene, necessidade de distanciamento social e promoção oportunista de medicamento sem eficácia comprovada. Portanto, foi possível observar como a obra voltou a colocar em discussão conceitos, temas, processos e controvérsias da ciência e da saúde, em um momento em que a população mundial foi submetida a uma radical transformação da vida cotidiana, vendo-se obrigada a adotar as rigorosas medidas citadas anteriormente e assimilar informações científicas.

Mas os resultados obtidos neste estudo vão além da mera precisão e do realismo de uma obra cinematográfica. Consideramos que a reflexão também deve ir ao encontro do sentido proposto por Davis (2017), para quem o cinema e a ciência podem ser tomados como meios de tornar a vida visível, de examinar e produzir conhecimento sobre ela, em um processo que pense a própria existência humana. É o mesmo sentido adotado por Piassi e Pietrocola (2009), ao afirmarem que a ficção científica é mais do que um possível recurso didático para o ensino de ciências; é um discurso social sobre a ciência, por conter visões, debates e questões a respeito das ciências no momento em que a obra foi produzida.

Portanto, encaramos as mudanças na percepção do público em relação a Contágio como indícios da reconfiguração ou do reposicionamento desse 
discurso, o que diz respeito exatamente ao aspecto contextual que caracteriza a apreensão dos bens culturais. As avaliações e os comentários, compartilhados com outros espectadores, em diferentes períodos e momentos, inserem o filme no debate público das plataformas digitais de comunicação, acionando temores individuais e coletivos dos mundos pré e pós-pandêmico.

Tal choque ou perplexidade se torna mais importante e eficaz quando o contrafactual que o produz estabelece uma ligação com o real em termos de possibilidades sustentadas pela razão, que é o que faz o discurso da FC [ficção científica]. [...] Não se trata de mero espanto e estranhamento frente ao incomum, que ocorre em histórias de terror ou fantasia, mas de um estranhamento que obriga a pensar no incomum como uma conjetura plausível e lógica, aplicável ao mundo fora da ficção (PIASSI; PIETROCOLA, 2009, p. 528).

Para esses autores, é na leitura crítica que a irrealidade da ficção se torna realidade sociocultural — realidade essa que, nos dias atuais, tem sido assentada sobre o tão propalado, mas ainda um tanto incógnito, "novo normal". Em nosso estudo, vimos que essa leitura crítica em relação ao filme Contágio foi subsidiada pela experiência real da pandemia de COVID-19, empreendida por um espectador que reflete e é refletido na tela, em uma espécie de diegese do mundo real.

Luisa Massarani é coordenadora do Instituto Nacional de Comunicação Pública da Ciência e Tecnologia e pesquisadora da Casa de Oswaldo Cruz (COC/ Fiocruz). É doutora na área de Gestão, Educação e Difusão em Biociências pela Universidade Federal do Rio de Janeiro (UFRJ)..

luisa.massarani@fiocruz.br

Luiz Felipe Fernandes Neves é doutorando no Programa de Pós-Graduação em Ensino em Biociências e Saúde do Instituto Oswaldo Cruz (IOC/Fiocruz). É mestre em Comunicação pela Universidade Federal de Goiás (UFG).

luiz.felipe@ufg.br 
Penélope Andreani Valadares é pesquisadora na área de Divulgação Científica no Instituto Nacional de Comunicação Pública da Ciência e Tecnologia. É mestre em Zoologia pelo Museu Nacional/UFRJ.

pepiandreani@hotmail.com

Contribuição de cada coautor: Luisa Massarani ficou responsável por: supervisão e gestão do Projeto de Pesquisa; fundamentação teórica e conceituação; análise formal do corpus; escrita - revisão e edição. Luiz Felipe Fernandes Neves ficou responsável por: metodologia; fundamentação teórica e conceituação; análise formal do corpus; escrita - Primeira Redação. Penélope Andreani Valadares ficou responsável por: análise formal do corpus; escrita - Primeira Redação.

\section{Referências}

ADOLFO, K. Contágio: Roteirista fala sobre filme que "previu" coronavírus. Adoro Cinema, 2020. Disponível em: <http://www.adorocinema.com/noticias/filmes/noticia-153521/>. Acesso em: 26 fev. 2021.

ANDREW, J. D. As principais teorias do cinema: uma introdução. Rio de Janeiro: Zahar, 2002.

ATOCHERO, A. V. Del COVID-19 al covid 2.0: el virus es el mensaje. In: Grupo de Investigación Corona Social (comp.). Ensayos desconfinados: ideas de debate para la post pandemia. Badajoz: Antropiqa, 2020. p. 11-34.

BAKER, A. Global Cinema and Contagion. Film Quarterly, v. 66, n. 3, p. 5-14, 2013.

BALBINOT, E. M.; MIQUELIN, Charlie Antoni. O cinema como agente: educação e aprendizagem por narrativas de epidemias. In: SEMINÁRIO NACIONAL CINEMA EM PERSPECTIVA, 2., 2013, Curitiba. Anais [...]. Curitiba: Unespar/fap, 2013. p. 1-20.

BARBOSA, J. L. Por uma quarentena de direitos para as favelas e as periferias! Espaço e Economia, n. 17, p. 1-4, 2020.

BENSON-ALLOTT, C. Out of Sight. Film Quarterly, v. 65, n. 2, p. 14-15, 2011.

BLANES, J. P. Ficciones inmunitarias: sobre la lógica de la inmunidad en la cultura contemporánea. Papeles del Ceic, v. 2018, n. 1, p. 1-32, 2018.

BORBA, E. M. B. O uso de filme como recurso pedagógico no estudo de epidemias: possibilidades na aprendizagem significativa. 2015. 94 f. Dissertação (Mestrado) - Curso de Mestrado Profissional em Formação Científica, Educacional e Tecnológica, Universidade Tecnológica Federal do Paraná, Curitiba, 2015. 
BUCHANAN, K. Steven Soderbergh e Amy Seimetz fizeram os filmes mais importantes sobre pandemias. Terra, 2020. Disponível em: <https://www.terra.com.br/diversao/cinema/ steven-soderbergh-e-amy-seimetz-fizeram-os-filmes-mais-importantes-sobre-pandemias, 11306f51506365683095422690a53154yo41 etlq.html>. Acesso em: 26 fev. 2021.

CAPPARROS, E. M.; MAGALHÃES JÚNIOR, C. A. O. A representação social sobre morcegos apresentada pela mídia brasileira. Contexto \& Educação, v. 30, n. 97, p. 94-116, 2015.

CASTELFRANCHI, Y. Computer-aided text analysis: na open-aired laboratory for social sciences. Journal of Science Communication, v. 16, n. 2, p. 1-11, 2017.

CLARK, T. Pandemic movie 'Contagion' is surging in popularity due to the coronavirus and has hit the No. 7 spot on iTunes. Insider, 2020. Disponível em: <https://www.businessinsider.com/coronavirus-contagion-movie-is-surging-in-piracy-rentals-on-itunes-2020-3>. Acesso em: 26 fev. 2021.

CONTÁGIO. Direção de Steven Soderbergh. Warner Bros, 2011.

DAVIS, M. "Is it Going to be Real?": narrative and media on a pandemic. Forum: Qualitative Social Research, v. 18, n. 1, p. 1-19, 2017.

DELEO, R. Democratizing public health: citizen empowerment through the biothriller genre. Catalyst: A Social Justice Forum, v. 4, n. 1, p. 1-17, 2014.

DIXON, D. P; JONES, J. P. The tactile topologies of Contagion. Transactions of the Institute of British Geographers, v. 40, n. 2, p. 223-234, 2014.

DOMínGUEZ, N. M.; CASTELLANOS, A. R. Pertinencia del análisis de la película Contagio (2011) en el aprendizaje de la metodología clínica y epidemiológica en medicina. Journal of Medicine and Movies, v. 12, n. 3, p. 147-155, 2016.

FAN, Yi et al. Bat Coronaviruses in China. Viruses, v. 11, n. 3, p. 1-14, 2019.

FERRÉ-SADURNÍ, L.; MCKINLEY, J. Alex Jones Is Told to Stop Selling Sham Anti-Coronavirus Toothpaste. The New York Times, 2020. Disponível em: <https://www.nytimes. com/2020/03/13/nyregion/alex-jones-coronavirus-cure.html>. Acesso em: 26 fev. 2021.

FIDALGO, S. S. Ciclo de mejora en el aula aplicado a la docencia universitaria de las enfermedades transmisibles en Salud Pública. In: JORNADAS DE FORMACIÓN E INNOVACIÓN DOCENTE DEL PROFESORADO, 2019, Anais [...]. Editorial Universidad de Sevilla, 2019. p. 1569-1591.

FOURNIER, G. The BBC and Disaster Films: from education to entertainment. Inmedia, $\mathrm{n}$. 72, p. 1-18, 2019.

GÓMEZ, P. A. La calamidad es un baile sin fin. Question/cuestión, v. 1, p. 1-7, 2020.

GOOGLE. Google Trends. 2020. Disponível em: <https://trends.google.com.br/ trends/?geo=BR>. Acesso em: $26 \mathrm{fev} .2021$. 
GRACEWOOD, G. The Curve. Letterboxd, 2020. Disponível em: <https://news.letterboxd. com/post/613161636990205952/the-curve-contagion>. Acesso em: 26 fev. 2021.

GRAVINA, M. G. P.; MUNK, M. Dinâmicas de oficinas de textos em Biologia: ferramentas para a alfabetização científica em tempos de fake news. Experiências em Ensino em Ciências, v. 14, n. 3, p. 612-620, 2019.

IMBERT, G. Imaginarios posapocalípticos en el cine actual: entre la vuelta al origen y el fin de la humanidad. Contratexto, Lima, n. 22, p. 75-89, 2014.

JUDENSNAIDER, I. Contágio: o discurso do medo. Prometeica, São Paulo, n. 6, p. 79-95, 2012.

KEANE, S. Disaster Movies: the cinema of catastrophe. Nova York: Columbia University Press, 2006.

KORTANJE, M. E. Contagio y pandemia: crónicas de un desastre apocalíptico. Revista de Antropologia Experimental, Jaén, n. 12, p. 261-270, 2012.

. La Función del Virus en el Capitalismo Mortuorio. In: JORNADAS DE SOCIOLOGIA, 7, 2017, Buenos Aires. Anais [...]. Buenos Aires: Universidad de Buenos Aires, 2017. p. 1-17.

LEE, B. Containing the Contagion: treating the virus that inspired the film. Science Translational Medicine, v. 3, n. 105, p. 1-6, 2011.

LETTERBOXD. Social film discovery. 2020. Disponível em: <https://letterboxd.com/>. Acesso em: 26 fev. 2021.

LOMAN, N.; GARDY, J. Contagion: a worthy entrant in the outbreak film genre. Biochemistry on Screen, p. 22-25, jan. 2015.

MAINERO, X. S.; COVARRUBIAS, V. G. Enfermedades infecciosas, hacia una medicina personalizada. Revista Digital Universitaria, Cidade do México, v. 15, n. 6, p. 1-9, 2014.

MARKENDORF, M.; FELIPPE, R. Ficções da peste: esboço para um estudo do imaginário ficcional das doenças. Revista Scripta Uniandrade, v. 16, n. 1, p. 309-331, 2018.

MARTÍNEZ, M. J. F. et al. Enseñanza de la medicina a través del cine: una dilatada experiencia. In: JORNADAS DE INNOVACIÓN DIDÁCTICA EN LA UNIVERSIDAD DE SALAMANCA, 2, 2013, Salamanca. Anais [...]. Salamanca: Universidad de Salamanca, 2013. p. 69-74.

MATHIJS, E. Referential acting and the ensemble cast. Screen, v. 52, n. 1, p. 89-96, 2011.

MENDONÇA, I. V. S.; PINHEIRO, L. C. Filme como estratégia propulsora para trabalhar noç̃̃es epidemiológicas no ensino de Biologia. In: CONGRESSO NACIONAL DE EDUCAÇÃO, 6., 2019, Fortaleza. Anais [...]. Fortaleza: Realize, 2019. p. 1-12.

MESSIAS, I. M. O. et al. Relato de experiência: the film as a teaching strategy. Brazilian Journal of Development, Curitiba, v. 5, n. 6, p. 4304-4317, jun. 2019.

MIQUELIN, C. A.; BALBINOT, Edilce Maria. Cinema e educação em ciências: uma perspectiva metodológica para os professores. Tecné, Episteme y Didaxis, número extraordinário, $p$. 1809-1818, 2014. 
MÜLLER, F. Inimigo invisível: a doença na literatura e no cinema. In: CONGRESSO INTERNACIONAL DA ABRALIC, 8., 2013, Campina Grande. Anais [...]. Campina Grande: Realize, 2013. p. 1-10.

OLIVEIRA, F.; GRAZINI, M. Filme de 2011 sobre pandemia dispara em plataforma da Claro. Folha de S. Paulo, 2020. Disponível em: <https://www1.folha.uol.com.br/colunas/ painelsa/2020/03/filme-de-2011-sobre-pandemia-dispara-em-plataforma-da-claro.shtml.> Acesso em: 26 fev. 2021.

PIASSI, L. P.; PIETROCOLA, M. Ficção científica e ensino de ciências: para além do método de 'encontrar erros em filmes'. Educação e Pesquisa, São Paulo, v. 35, n. 3, p. 525-540, 2009.

POKORNOWSKI, S. Insecure Lives: zombies, global health, and the totalitarianism of generalization. Literature and Medicine, v. 31, n. 2, p. 216-234, 2013.

ROJAS, J. E. Breves reflexiones sobre las imágenes del miedo al fin del mundo: el caso de las pandemias en la pantalla. Rev. Filosofía Univ. Costa Rica, n. 145, p. 37-44, 2017.

SCRIVNER, C. An Infectious Curiosity: morbid curiosity and media preferences during a pandemic [pré-print]. PsyArXiv, p. 1-14, 2020.

SIKORA, T. Bodies out of rule: transversal readings in canadian literature and film. Kraków: Wydawnictwo Naukowe Uniwersytetu Pedagogicznego, 2014.

SILVA JÚNIOR, C. A. O pensamento evolutivo como invariante universal em biologia estruturando o ensino de citologia em nível médio. 2016. 74 f. Dissertação (Mestrado) - Curso de Mestrado em Ensino em Ciências, Universidade Federal de Uberlândia, Uberlândia, 2016.

SPERLING, N. 'Contagion,' Steven Soderbergh's 2011 Thriller, Is Climbing Up the Charts. The New York Times, 2020. Disponível em: <https://www.nytimes.com/2020/03/04/business/ media/coronavirus-contagion-movie.html>. Acesso em: 26 fev. 2021.

SUGIERA, M. Theatre as Contagion: making sense of communication in performative arts. Text Matters, n. 7, p. 291-304, 2017.

VENTOSA, R. F. Infección controlada: maneras de representar el estado de excepción en el cine de pandemias. Laocoonte: Revista de Estética y Teoría de las Artes, v. 2, n. 2, p. 189-205, 2015.

WHO. Naming the coronavirus disease (COVID-19) and the virus that causes it. World Health Organization, 2020a. Disponível em: <https://www.who.int/emergencies/diseases/ novel-coronavirus-2019/technical-guidance/naming-the-coronavirus-disease-(covid-2019)-and-the-virus-that-causes-it>. Acesso em: 26 fev. 2021.

WHO. Pneumonia of unknown cause - China. World Health Organization, 2020b. Disponível em: <https://www.who.int/csr/don/05-january-2020-pneumonia-of-unkown-cause-china/ en/>. Acesso em: 26 fev. 2021. 
artigo | "Pare de tocar seu rosto!": as mudanças na percepção dos espectadores do filme Contágio com a pandemia de COVID-19

WHO. Statement on the second meeting of the International Health Regulations (2005) Emergency Committee regarding the outbreak of novel coronavirus (2019nCoV). World Health Organization, 2020c. Disponível em: <https://www.who.int/news/ item/30-01-2020-statement-on-the-second-meeting-of-the-international-health-regulations-(2005)-emergency-committee-regarding-the-outbreak-of-novel-coronavirus-(2019-ncov)>. Acesso em: 26 fev. 2021.

WORLDOMETER. COVID-19 Coronavirus Pandemic. 2021. Disponível em: <https://www. worldometers.info/coronavirus/?>. Acesso em: 26 fev. 2021.

Artigo recebido em 27/02/2021 e aprovado em 18/05/2021. 